\title{
Correspondence
}

\section{Normal bruises in pre-school children}

Sir,

I recently conducted a pilot study of normal bruises in normal 3- to 4-year-old children in a Manchester day nursery. A group of 6 children was examined over a period of six weeks and bruises and other signs of trauma recorded. The results will be familiar to every parent, as well as to every clinician seeing children, but for me they were a salutary experience in relation to child abuse.

No child had fewer than three bruises at each of the 60 examinations. Certainly shins, knees, and elbows were common sites but finger-tip size bruises over the lumbar spine were seen in all 6 children, and bruising over the biceps and scapulae were also common. Explanations were often highly improbable and totally believable, including 'Fischer-Technic rocket', and for a $10 \times 1 \mathrm{~cm}$ bruise on the buttock 'missed pot sit'. As far as I know no child suffered abuse during the period of observation.

I recommend this exercise to anyone concerned with child abuse; it highlights pathological trauma just as it is possible to contrast accidental and nonaccidental trauma when abused children are admitted to the lively community of a children's ward.

I thank Mrs Ryder and her staff at Nuthurst Road Day Nursery, and her superiors who authorised my visits.

JOHN H KEEN

Booth Hall Children's Hospital, Charlestown Road, Blackley, Manchester M9 $2 A A$

\section{Infection associated with peritoneal dialysis}

Sir,

The paper by Coulthard ${ }^{1}$ reaffirmed that treatment with heparin does not enhance recovery from renal failure in haemolytic-uraemic syndrome (HUS) -in fact, it may even be hazardous. Recent literature ${ }^{2}$ cites improved rates of survival among affected children, and dialysis seems to be an important adjunct to the therapy responsible for a decrease in the mortality rates.

Coulthard's work showed that if dialysis is instituted most children with HUS need longer than 48 hours' treatment. This necessitates very careful observation of the patients' condition to guard against infection. Six of the 9 patients treated with dialysis by Coulthard developed peritoneal infection, and all needed treatment with gentamicin; in one patient the catheter had to be removed as well. This very high incidence of infection is disturbing and unacceptable with the prevailing methods of asepsis. The type of peritoneal catheters used was not mentioned and so I assume that they were non-cuffed and left in place throughout treatment. The care of such catheters is very demanding, and risk of infection exists despite meticulous care. I think that the use of a double-cuffed Tenckhoff catheter could cut down the chances of infecting the peritoneal cavity in cases where more than 48 hours of dialysis is needed. Although these catheters are designed primarily for use in chronic peritoneal dialysis, their application in acute renal failure is not contraindicated. If taken at the onset, such a preventive step will go a long way towards reducing infectious complications in patients in whom a relatively long period of dialysis is needed during the course of acute renal shutdown.

\section{References}

1 Coulthard M G. An evaluation of treatment with heparin in the haemolytic-uraemic syndrome successfully treated by peritoneal dialysis. Arch Dis Child 1980; 55: 393-7.

2 Gianantonio C A, Vitacco M, Mendilaharzu F, Gallo G E, Sojo E T. The hemolytic-uremic syndrome. Nephron 1973; 11: 174-92.

\section{K K KHER \\ Medical College of Wisconsin, Division of Nephrology, Department of Pediatrics, 8700 West Wisconsin Avenue, Milwaukee, \\ Wisconsin 53226, USA}

\section{Dr Coulthard comments:}

Dr Kher's assumption that our patients were treated using non-cuffed catheters is correct. I agree that the high infection rate gives cause for concern despite the fact that early detection by microscopical examination of effluent dialysate meant that only one patient developed clinical evidence of peritonitis. In the other cases infection was cleared promptly and dialysis continued uninterrupted.

Since submitting the paper we have successfully treated another 8 children with the haemolytic-uraemic syndrome without using heparin, and 6 required peritoneal dialysis for similar periods to those reported in our previous patients. In 2 of them, bacteria were cultured from the dialysis fluid and one child developed symptoms of peritonitis which led us to remove the catheter.During the same time we have inserted 5 Tenckhoff catheters in children undergoing chronic peritoneal dialysis, none of whom developed similar problems while in hospital.

I would therefore support $\mathrm{Dr}$ Kher in advocating the use of Tenckhoff catheters in the haemolytic-uraemic syndrome.

M G Coulthard Princess Mary Maternity Hospital, Great North Road, Newcastle upon Tyne NE2 3BD 